\title{
Skimmed, sterilized, and concentrated bovine late colostrum promotes both prevention and recovery from intestinal tissue damage in mice
}

\author{
Cairangzhuoma, ${ }^{*}$ M. Yamamoto, $†$ H. Muranishi, $†$ M. Inagaki, $†$ K. Uchida, $\ddagger$ K. Yamashita, $\ddagger$ S. Saito, $†$ \\ T. Yabe ${ }^{*} \dagger$ and Y. Kanamaru* ${ }^{1}$ \\ *United Graduate School of Agricultural Science, and \\ †Faculty of Applied Biological Sciences, Gifu University, 1-1 Yanagido, Gifu, Gifu 501-1193, Japan \\ †Central R\&D Laboratory, Kobayashi Pharmaceutical Co. Ltd., Ibaraki, Osaka 567-0057, Japan
}

\begin{abstract}
Bovine colostrum is a rich source of tissue repair and growth factors, and inhibits gastrointestinal injury induced by the side effects of nonsteroidal antiinflammatory drugs (NSAID), such as indomethacin. Nonsteroidal antiinflammatory drugs are drugs with analgesic and antipyretic effects, but in higher doses they have inflammatory effects. The pathogenesis of small intestinal damage caused by NSAID is unclear. The present study was performed to investigate the antiinflammatory effects of skimmed, sterilized, and concentrated bovine late colostrum on intestinal injury induced by side effects of NSAID, and then to identify the active ingredient in the colostrum for intestinal tissue. In Japan, the sale of bovine colostrum within $5 \mathrm{~d}$ after parturition is prohibited by law. Therefore, we focused on bovine late colostrum obtained from healthy lactating cows 6 to $7 \mathrm{~d}$ after parturition. Proliferation of small intestine epithelial cells was stimulated in mice fed the colostrum for $1 \mathrm{wk}$. With regard to indomethacin-induced enteropathy, both prefeeding and postfeeding with colostrum facilitated growth of the intestinal villi, indicating preventive and healing effects. Furthermore, to identify the active ingredient in the colostrum responsible for this effect, the casein and whey fractions were prepared from the colostrum and fed to normal mice. Only the colostrum casein fraction stimulated intestinal villus elongation, whereas the whey fraction and mature milk casein showed no such effect. Taken together, these observations indicate that the skimmed, sterilized, and concentrated bovine late colostrum, especially the casein fraction, could be used to treat the injurious effects of NSAID in the intestine and could be effective for treatment of other ulcerative conditions in the bowel, suggesting that the colostrum has therapeutic potential for intestinal inflammation.
\end{abstract}

Received May 7, 2012.

Accepted November 4, 2012.

${ }^{1}$ Corresponding author: kanamaru@gifu-u.ac.jp
Key words: bovine late colostrum, indomethacin, intestinal injury, milk protein

\section{INTRODUCTION}

Colostrum is the milk produced by female mammals during the first few days after giving birth and is rich in immunoglobulins, growth factors, antimicrobial proteins such as lactoferrin, and a variety of other antimicrobial factors, including interferons, iron-binding proteins, polymorphonuclear leukocytes, macrophages, and lymphocytes (Playford et al., 1999). Compared with mature milk, colostrum contains higher levels of growth-promoting proteins (Lee et al., 2008). Colostrum is useful for treating a wide variety of intestinal disorders, including inflammatory bowel disease (Khan et al., 2002), nonsteroidal antiinflammatory drug (NSAID)-induced gut injury (Playford et al., 1999), viral gastroenteritis (Sarker et al., 1998; Huppertz et al., 1999), and chemotherapy-induced mucositis (Howarth et al., 1996). Several clinical studies have suggested that bovine colostrum may have antiinflammatory effects in various intestinal inflammatory disorders (An et al., 2009).

However, the sale of bovine colostrum within $5 \mathrm{~d}$ after parturition is prohibited by law in Japan. Therefore, we evaluated the protective and recovery efficacy of skimmed and concentrated bovine late colostrum (SCBLC), which can be used as a food in Japan, obtained from healthy lactating cows on d 6 to 7 after parturition. Bovine colostrum inhibits binding of norovirus-like particles to human intestinal Caco-2 cells (Murakami et al., 2010). We also previously reported that bovine late colostrum could prevent the development of diarrhea caused by rotaviruses (Inagaki et al., 2010). However, the active ingredients in the colostrum are still not clear.

Casein accounts for $80 \%$ of bovine milk proteins. On the other hand, immunoglobulins make the largest contribution to protein content in bovine colostrum, with $\alpha-\mathrm{LA}$ and casein contributing lesser amounts (Kelly, 
2003). The contribution of immunoglobulins will decline substantially in any bovine colostrum collected more than $24 \mathrm{~h}$ postparturition and the amounts of $\alpha-\mathrm{LA}$ and casein will increase proportionately (Kelly, 2003).

The pathogenesis of small intestinal damage caused by NSAID is unclear. Therefore, currently no therapeutic strategy exists for ameliorating such damage (Fukumoto et al., 2011). Mucosal damage of the small intestine is one of the major adverse effects of NSAID, such as indomethacin (IND) and aspirin (Fang et al., 1977; Robert and Asano, 1977; Bjarnason et al., 1987). Intestinal injury induced by IND is associated with increased mucosal permeability, microvascular injury, focal intravascular thrombus formation, fibrin deposition, and neutrophil infiltration.

We hypothesized that SCBLC may suppress intestinal inflammation and may be useful as an antiinflammatory agent for treating diseases caused intestinal inflammation. The present study was performed to investigate whether oral administration of SCBLC to mice can ameliorate small intestinal inflammation induced by NSAID such as IND, and then to identify the active ingredient in the colostrum for intestinal cells.

\section{MATERIALS AND METHODS}

\section{Bovine Milk Samples}

Bovine normal milk was collected from healthy Holstein-Friesian cows held at Gifu University Farm (Gifu, Japan), and then maintained at $-20^{\circ} \mathrm{C}$ until processing. Skimmed and concentrated bovine late colostrum from normal cows was prepared at an industrial level in the facility of Kobayashi Pharmaceutical Co. Ltd. (Osaka, Japan). Briefly, the pooled late colostrum from healthy cows 6 to $7 \mathrm{~d}$ after parturition was defatted by centrifugation, pasteurized by heating at $73^{\circ} \mathrm{C}$ for $15 \mathrm{~s}$, and then concentrated by UF, followed by spray drying.

\section{Isolation of Casein and Whey from Milk Samples}

Skimmed and concentrated bovine late colostrum and normal milk were acidified to $\mathrm{pH} 4.6$ using $4 \mathrm{~N} \mathrm{HCl}$ at room temperature, and then centrifuged at $12,000 \times$ $g$ for $30 \mathrm{~min}$ at $25^{\circ} \mathrm{C}$. Skimmed and concentrated bovine late colostrum casein and normal milk casein were obtained as the acid precipitate and SCBLC whey was obtained as the supernatant. Both caseins were dialyzed using a membrane with molecular weight cut-off of 6,000 to 8,000 (Spectrum Laboratories Inc., Rancho Dominguez, CA) against distilled water for $3 \mathrm{~d}$ at $4^{\circ} \mathrm{C}$, and then finally lyophilized.

\section{Animals}

Adult female BALB/c mice (6 to 7 wk old; BW: 15 to $18 \mathrm{~g}$ ) were purchased from Japan SLC Inc. (Shizuoka, Japan), and were kept in an air-conditioned room with a 12-h light-dark cycle under specific pathogen-free conditions during the experimental period. All animals were bred under these conditions with a solid diet (Clea Japan Inc., Tokyo, Japan) and water ad libitum for $1 \mathrm{wk}$, and then normal-feeding, healthy animals were used for the experiments. All experimental methods and procedures were conducted according to the Guidelines for Animal Experiments in Gifu University, and all animal experiments were approved by the Animal Experimental Committee of the Faculty of Applied Biological Sciences at Gifu University.

\section{Examination of the Efficacy of SCBLC on the Normal Small Intestine}

Nine mice ( 7 wk old) were divided into 3 groups: control $(\mathrm{n}=3), 5 \mathrm{mg}$ of SCBLC $/ \mathrm{mL}(\mathrm{n}=3)$, and 10 $\mathrm{mg}$ of SCBLC/mL $(\mathrm{n}=3)$ groups. For SCBLC groups, animals were allowed to drink 5 or $10 \mathrm{mg}$ of SCBLC/ $\mathrm{mL}$ ad libitum instead of water for $6 \mathrm{~d}$. Skimmed and concentrated bovine late colostrum was exchanged every day. The control group was given water instead of SCBLC. All groups were allowed to eat a solid diet ad libitum during the experimental period. On $\mathrm{d} 7$, all animals were anesthetized with $30 \mathrm{~mL} / \mathrm{kg}$ of $3 \%$ chloral hydrate (Wako Pure Chemical Industries Ltd., Osaka, Japan), and killed by transcardial perfusion of physiological saline, followed by $4 \%$ paraformaldehyde in $0.1 M$ PBS ( $\mathrm{pH}$ 7.4). A 0.5-cm length of the jejunum was then collected from the middle region of the small intestine in each animal and immersed in the same fixative solution overnight at $4^{\circ} \mathrm{C}$. The specimens were dehydrated, embedded in paraffin, sectioned coronally at a thickness of $5 \mu \mathrm{m}$, and processed for histological examination as described below (see test 1 in Figure 1).

\section{Examination of the Prefeeding Effect of SCBLC on IND-Induced Enteropathy}

Twenty-four mice (7 wk old) were divided into 4 groups: control $(\mathrm{n}=6)$, IND $(\mathrm{n}=6), 5 \mathrm{mg}$ of SCBLC/ $\mathrm{mL}(\mathrm{n}=6)$, and $10 \mathrm{mg}$ of $\mathrm{SCBLC} / \mathrm{mL}(\mathrm{n}=6)$ groups. For SCBLC groups, animals were allowed to drink 5 or $10 \mathrm{mg}$ of $\mathrm{SCBLC} / \mathrm{mL}$ ad libitum instead of water for $1 \mathrm{wk}$, whereas the control and IND groups were given water. All groups were allowed to eat a solid diet ad libitum during the experimental period. On d 7, the IND and both SCBLC groups were subcutaneously 


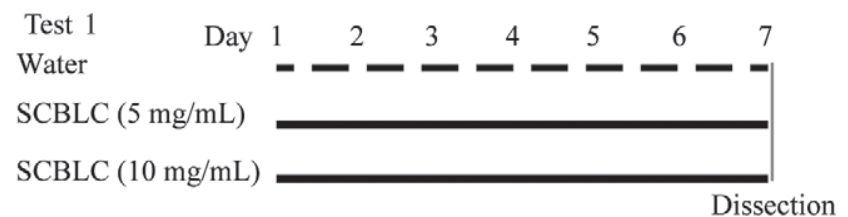

Test 2
$\begin{aligned} & \text { Water } \\ & \operatorname{IND}\end{aligned}$
$\operatorname{SCBLC}(5 \mathrm{mg} / \mathrm{mL})$
$\operatorname{SCBLC}(10 \mathrm{mg} / \mathrm{mL})$

Dissection

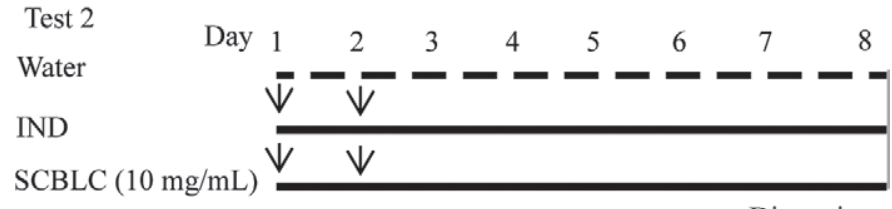

Dissection

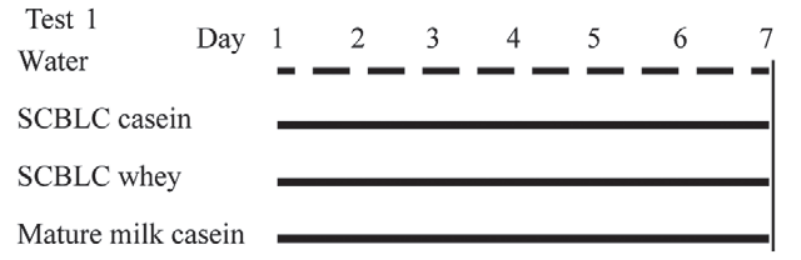

Dissection

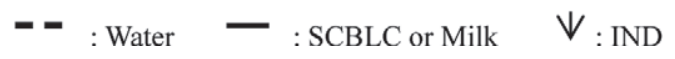

Figure 1. Experimental schedule. All animals were given a solid diet and water ad libitum for $1 \mathrm{wk}$ before the experiment. The broken line indicates the period when mice were given water instead of skimmed and concentrated bovine late colostrum (SCBLC). The solid line indicates the period when mice were given SCBLC or milk. The arrow indicates the point of indomethacin (IND) injection.

administered a high concentration of IND (85 mg/ kg; Wako Pure Chemical Industries Ltd.) dissolved in dimethyl sulfoxide (DMSO; Wako Pure Chemical Industries Ltd.) to induce acute enteropathy (Playford et al., 1999). On d 8, all animals were anesthetized with $30 \mathrm{~mL} / \mathrm{kg}$ of $3 \%$ chloral hydrate (Wako Pure Chemical Industries Ltd.) and killed by transcardial perfusion of physiological saline, followed by $4 \%$ paraformaldehyde in $0.1 M$ PBS (pH 7.4). A 0.5-cm length of the jejunum was then collected from the middle region of the small intestine in each animal and immersed in the same fixative solution overnight at $4^{\circ} \mathrm{C}$. The specimens were dehydrated, embedded in paraffin, sectioned coronally at a thickness of $5 \mu \mathrm{m}$, and processed for histological examination as described below (see test 2 in Figure 1).

\section{Examination of the Postfeeding Effect of SCBLC on IND-Induced Enteropathy}

Fifteen mice ( 8 wk old) were divided into 3 groups: control $(\mathrm{n}=5)$, IND $(\mathrm{n}=5)$, and $10 \mathrm{mg}$ of SCBLC/ $\mathrm{mL}(\mathrm{n}=5)$ groups. On $\mathrm{d} 1$ and $2,20 \mathrm{mg} / \mathrm{kg}$ of IND dissolved in DMSO was administered subcutaneously into the IND and $10 \mathrm{mg}$ of $\mathrm{SCBLC} / \mathrm{mL}$ groups. The control group was administered DMSO instead of IND on $\mathrm{d} 1$ and 2 . The concentration of IND that permitted mice to survive during the experimental period was determined by preliminary experiments and based on a related study (Miura et al., 2007). From d 2 to 8, the SCBLC group was given $10 \mathrm{mg}$ of SCBLC $/ \mathrm{mL}$ ad libitum, whereas the control and IND groups were given water. All groups were allowed to eat a solid diet ad libitum during the experimental period. On d 8, paraffin sections of the jejunum from each animal were prepared as described above for histochemical examination (see test 3 in Figure 1).

\section{Examination of the Efficacy of SCBLC Casein and Whey on the Normal Small Intestine}

Nine mice ( 7 wk old) were divided into 4 groups: control $(\mathrm{n}=3), 10 \mathrm{mg}$ of SCBLC casein/mL $(\mathrm{n}=3)$, $10 \mathrm{mg}$ of SCBLC whey $/ \mathrm{mL}(\mathrm{n}=3)$, and $10 \mathrm{mg}$ of milk casein $/ \mathrm{mL}(\mathrm{n}=3)$ groups. All groups were allowed to eat a solid diet ad libitum during the experimental period. On d 7, all animals were anesthetized with 30 $\mathrm{mL} / \mathrm{kg}$ of $3 \%$ chloral hydrate (Wako Pure Chemical Industries Ltd.) and killed by transcardial perfusion of physiological saline, followed by $4 \%$ paraformaldehyde in 0.1 M PBS (pH 7.4). A 0.5-cm length of the jejunum was then collected from the middle region of the small intestine in each animal and immersed in the same fixative solution overnight at $4^{\circ} \mathrm{C}$. The specimens were dehydrated, embedded in paraffin, sectioned coronally at a thickness of $5 \mu \mathrm{m}$, and processed for histological examination as described below (see test 4 in Figure 1).

\section{Histological Examination}

The intestinal villus length and the percentage of proliferating cell nuclear antigen (PCNA)-positive cells in the intestinal villus were examined in paraffin sections. At least 6 sections, each of which was distant enough to avoid double counting of the same intestinal villus, were obtained from an individual animal. Half of the sections from each animal examined were stained with hematoxylin and eosin $(\mathbf{H E})$ to evaluate the intestinal villus length. The remaining half was analyzed using a PCNA staining kit (Invitrogen Corp., Carlsbad, CA) to 
Table 1. Villus length and proliferating cell nuclear antigen (PCNA)-positive cells (\%) from examined effects of skimmed and concentrated bovine late colostrum (SCBLC) on the normal small intestine and indomethacin (IND)-induced small intestine inflammation

\begin{tabular}{|c|c|c|c|}
\hline Test & Sample & $\begin{array}{l}\text { Villus length } \\
\qquad(\mu \mathrm{m})\end{array}$ & $\begin{array}{c}\text { PCNA-positive cell } \\
(\%)\end{array}$ \\
\hline \multirow[t]{3}{*}{ Test $1(\mathrm{n}=3)$} & Water & $130.1 \pm 6.7^{\mathrm{a}}$ & $50.0 \pm 13.2^{\mathrm{a}}$ \\
\hline & SCBLC $(5 \mathrm{mg} / \mathrm{mL})$ & $143.1 \pm 14.2^{\mathrm{b}}$ & $66.5 \pm 9.2^{\mathrm{b}}$ \\
\hline & SCBLC $(10 \mathrm{mg} / \mathrm{mL})$ & $149.1 \pm 18.1^{\mathrm{b}}$ & $65.6 \pm 10.3^{\mathrm{b}}$ \\
\hline \multirow[t]{4}{*}{ Test $2(\mathrm{n}=6)$} & Water & $116.8 \pm 18.6^{\text {ac }}$ & $51.3 \pm 5.7^{\mathrm{ac}}$ \\
\hline & IND & $88.9 \pm 33.6^{\mathrm{b}}$ & $46.5 \pm 7.9^{\mathrm{b}}$ \\
\hline & SCBLC (5 mg/mL) & $98.4 \pm 30.8^{\mathrm{b}}$ & $4.3 \pm 7.4^{\mathrm{ac}}$ \\
\hline & SCBLC $(10 \mathrm{mg} / \mathrm{mL})$ & $124.5 \pm 38.2^{\mathrm{ac}}$ & $59.2 \pm 9.0^{\mathrm{d}}$ \\
\hline \multirow[t]{3}{*}{ Test $3(\mathrm{n}=5)$} & Water & $153.0 \pm 29.2^{\mathrm{a}}$ & $58.6 \pm 15.4^{\mathrm{a}}$ \\
\hline & IND & $118.0 \pm 36.7^{\mathrm{b}}$ & $43.9 \pm 13.2^{\mathrm{b}}$ \\
\hline & SCBLC $(10 \mathrm{mg} / \mathrm{mL})$ & $189.0 \pm 46.9^{\mathrm{c}}$ & $63.4 \pm 21.5^{\mathrm{c}}$ \\
\hline \multirow[t]{4}{*}{ Test $4(\mathrm{n}=3)$} & Water & $145.0 \pm 20.8^{\mathrm{ac}}$ & $35.8 \pm 7.9^{\mathrm{ac}}$ \\
\hline & SCBLC casein $(10 \mathrm{mg} / \mathrm{mL})$ & $170.0 \pm 33.1^{\mathrm{b}}$ & $58.0 \pm 11.4^{\mathrm{b}}$ \\
\hline & SCBLC whey $(10 \mathrm{mg} / \mathrm{mL})$ & $120.1 \pm 34.1^{\mathrm{ac}}$ & $39.9 \pm 7.4^{\text {ac }}$ \\
\hline & Mature milk casein $(10 \mathrm{mg} / \mathrm{mL})$ & $123.0 \pm 29.3^{\mathrm{c}}$ & $35.8 \pm 10.2^{\mathrm{c}}$ \\
\hline
\end{tabular}

${ }^{\mathrm{a}-\mathrm{d}}$ Values within a column with different superscript letters are significantly different $(P<0.05)$.

evaluate the percentage of PCNA-positive cells in the intestinal villi. Briefly, the sections were deparaffinized, rehydrated, incubated with $3 \% \mathrm{H}_{2} \mathrm{O}_{2}$ in methanol for 10 min to eliminate endogenous peroxidase activity of the tissue, and rinsed 3 times in PBS for 2 min each time. The sections were then incubated with blocking solution supplied with the kit for $10 \mathrm{~min}$. After blotting off excess solution, the sections were incubated for $60 \mathrm{~min}$ with biotinylated anti-PCNA primary antibody supplied with the kit without any dilution. After rinsing in PBS, the sections were incubated with streptavidinperoxidase solution supplied with the kit for $10 \mathrm{~min}$. The sections were then rinsed in PBS and incubated for 5 min with a mixture of substrate buffer, chromogen solution (3,3'-diaminobenzidine tetrahydrochloride; $\mathrm{DAB}$ ) and hydrogen peroxide (final concentration of $0.03 \%$ ) supplied with the kit. Finally, the sections were counterstained with hematoxylin, dehydrated, covered with a coverslip using Histomount supplied with the kit, and observed by microscopy (BX52; Olympus, Tokyo, Japan) equipped with a digital camera (DP-71; Olympus).

\section{Statistical Analysis}

The intestinal villus length was measured on digital images of HE-stained sections in each animal. The intestinal villus length was measured in each animal (70 villi/mouse). To determine the percentage of PCNApositive cells in the intestinal villi, the total number of cells as well as the number of PCNA-positive cells in the intestinal villi were counted on digital images of counterstained sections, and then the ratio of the PCNA-positive cells to the total number of cells was calculated for each animal (50 villi/mouse). The differ- ences in intestinal villus length and the percentages of PCNA-positive cells among the groups in each experiment were evaluated by one-way ANOVA and post hoc Fisher probable least-squares difference (PLSD) tests. In all analyses, $P<0.05$ was taken to indicate statistical significance.

\section{RESULTS}

\section{Efficacy of SCBLC in the Normal Small Intestine}

In this experiment, mice were divided into 3 groups. Each of the controls was given water, whereas SCBLC groups were given either $5 \mathrm{mg} / \mathrm{mL}$ or $10 \mathrm{mg} / \mathrm{mL}$ of SCBLC for $6 \mathrm{~d}$. On $\mathrm{d} 7$, the jejunums of all animals were dissected, and then the intestinal villus length and the percentage of PCNA-positive cells in the intestinal villi by $\mathrm{HE}$ and PCNA staining were examined in each animal.

Neither damage nor pathological symptoms were found in the histology of each animal. The intestinal villus length in SCBLC-treated groups seemed to be longer than that in the water group (Figure 2A). The differences in intestinal villus length among the groups were significant by one-way ANOVA, and the post hoc Fisher PLSD test indicated that the villus length in groups treated with SCBLC at both concentrations was significantly longer than that in the control group (test 1 in Table 1). Proliferating cell nuclear antigen immunoreactivity was found exclusively in the cells located in the intestinal crypts of the animals examined (Figure 2B). The percentages of PCNA-positive cells were also significantly different among the 3 groups by one-way ANOVA, and the post hoc Fisher PLSD test indicated that the percentages in both $5 \mathrm{mg} / \mathrm{mL}$ and $10 \mathrm{mg} /$ 
$\mathrm{mL}$ of SCBLC groups were significantly different from that in the control group (see test 1 in Table 1). These results indicate that feeding with SCBLC facilitated the proliferation of immature epithelial cells in the intestinal crypt, leading to growth of the intestinal villus in the normal adult mouse small intestine.

\section{Prefeeding Effect of SCBLC on Indomethacin-Induced Enteropathy}

In this experiment, mice were divided into 4 groups. Each of the controls and the IND group were given water, whereas SCBLC groups were given either 5 or $10 \mathrm{mg}$ of $\mathrm{SCBLC} / \mathrm{mL}$ for $1 \mathrm{wk}$. On d 7 ( $6 \mathrm{~d}$ after the first feeding), the IND and the 5 and $10 \mathrm{mg}$ of SCBLC/ $\mathrm{mL}$ groups were given high-concentration indomethacin subcutaneously $(85 \mathrm{mg} / \mathrm{kg}$ ) to induce acute and severe enteropathy, whereas the control group remained untreated. On d 8, the jejunums of all animals were dissected and processed for histological examination by the HE and PCNA staining method.

The intestinal villi in the control group did not show any damage or pathological symptoms (Figure 3Aa). On the other hand, the villus length was shortened and the epithelial cells covering the tips of the villi were frequently broken in most of the villi in the IND group (Figure $3 \mathrm{Ab}$ ). The destruction of villi observed in the IND group was not seen in the groups treated with either concentration of SCBLC (Figure 3Ac and d). The intestinal villus length among these groups was also significantly different by one-way ANOVA (see test 2 in Table 1). The length in the $5 \mathrm{mg}$ of SCBLC $/ \mathrm{mL}$ group was not significantly different from that in the IND group, but the length in the $10 \mathrm{mg}$ of SCBLC/ $\mathrm{mL}$ group was significantly longer than those in the 5 $\mathrm{mg}$ of SCBLC $/ \mathrm{mL}$ and IND groups. The expression of PCNA in each group was also examined (Figure 3B). Proliferating cell nuclear antigen-positive cells were found exclusively in the intestinal crypts in each group, and the percentages of PCNA-positive cells were significantly different among these 4 groups by one-way ANOVA (see test 2 in Table 1). The percentage in the IND group was significantly lower than that in the control group. On the other hand, the percentage in the 10 $\mathrm{mg}$ of SCBLC/mL group was significantly larger than those in any of the other groups. In addition, the percentage in the $5 \mathrm{mg}$ of $\mathrm{SCBLC} / \mathrm{mL}$ group was greater than that in the IND group. These results indicate that prefeeding with SCBLC exerted a protective effect on the intestinal villus, and prefeeding of an appropriate concentration of SCBLC can prevent villus injury in this model of acute enteropathy induced by administration of a high concentration of IND.

\section{Postfeeding Effect of SCBLC on Indomethacin-Induced Enteropathy}

The postfeeding effect of SCBLC after IND-induced enteropathy was also examined in this study. The mice were divided into 3 groups: the IND and $10 \mathrm{mg}$ of SCBLC/mL groups were subcutaneously treated with IND $(20 \mathrm{mg} / \mathrm{kg}$ of BW) to induce chronic enteropathy that permits mice to live for the experimental period on $\mathrm{d} 1$ and 2. As a control, only DMSO, which was the solvent used for IND, was injected instead of IND. From d 2 to 8 , the control and IND groups were given water instead of $10 \mathrm{mg}$ of SCBLC/mL. On d 8 , the jejunums of all animals were dissected and processed for histological examination by the HE and PCNA staining method.

Figure 4 shows the histological appearance of the intestinal villi in each group. Neither damage nor pathological symptoms were found in the control (Figure $4 \mathrm{Aa}$ ) or SCBLC groups (Figure $4 \mathrm{Ac}$ ). On the other hand, the villus length was shortened in the IND group (Figure $4 \mathrm{Ab}$ ). The intestinal villus lengths were significantly different among these 3 groups by one-way ANOVA (see test 3 in Table 1). The villus length in the IND group was significantly shorter than those in the control and SCBLC groups. On the other hand, the villus length in the SCBLC group was significantly longer than not only that in the IND group, but also that in the control group. The differences in percentages of PCNA-positive cells among these groups were similar to those in the intestinal villus length. The PCNA-positive cells were distributed exclusively in the intestinal crypts in each group (Figure 4B), and the percentages of PCNA-positive cells were significantly different among these groups by one-way ANOVA (test 3 in Table 1). The percentage in the IND group was significantly lower than those in the control and SCBLC groups. On the other hand, the percentage in the SCBLC group was significantly larger than not only that in the IND group, but also that in the control group. These results indicate that the intestinal villus insult induced by IND could be ameliorated by immediate and continuous feeding with SCBLC after IND-induced enteropathy.

\section{Effects of SCBLC Casein and Whey on the Normal Small Intestine}

To identify the active ingredient of SCBLC, mice were given casein and whey $(10 \mathrm{mg} / \mathrm{mL})$ separated from SCBLC and we examined the effects of their feeding on the normal small intestine in comparison with water or casein $(10 \mathrm{mg} / \mathrm{mL})$ obtained from mature milk for $6 \mathrm{~d}$. 
1352

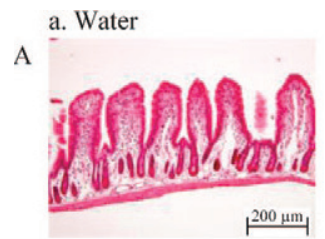

b. SCBLC $(5 \mathrm{mg} / \mathrm{mL})$
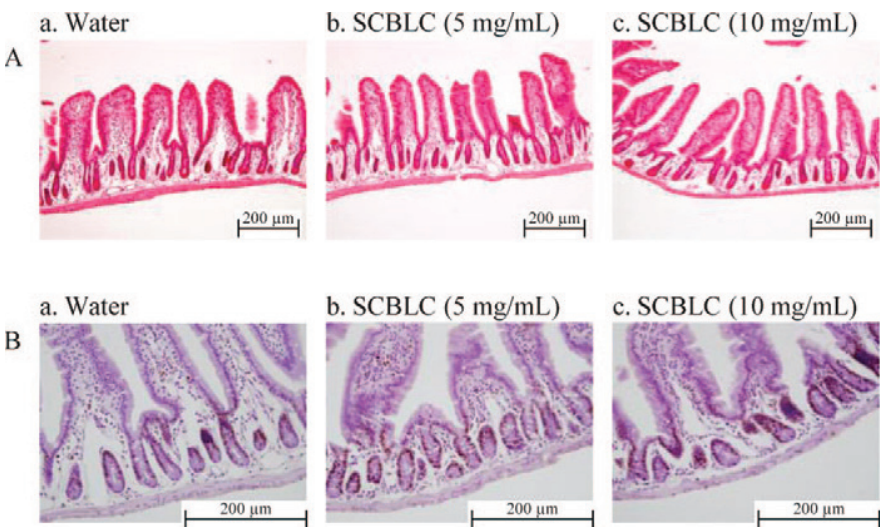

Figure 2. Effects of skimmed and concentrated bovine late colostrum (SCBLC) on the normal small intestine in mice. Figure 2A shows hematoxylin and eosin staining of the jejunum of mice. Figure $2 \mathrm{~B}$ shows immunostaining for proliferating cells in the jejunum of mice for nuclear antigen (proliferating cell nuclear antigen, PCNA). Mice were fed water as a control (a), $5 \mathrm{mg}$ of SCBLC/mL (b), or $10 \mathrm{mg}$ of $\mathrm{SCBLC} / \mathrm{mL}$ (c) for $6 \mathrm{~d}$. Brown cells are positive and blue cells are negative. The bars indicate $200 \mu \mathrm{m}$.

Then, the villus length and the percentage of PCNApositive cells in the intestinal villi were measured in each animal by the HE and PCNA staining method.

Neither damage nor pathological symptoms were found histologically in any of these groups. However, the villi seemed to be longer in the $10 \mathrm{mg}$ of SCBLC casein $/ \mathrm{mL}$ group than in any of the other groups (Figure 5A). Indeed, the intestinal villus lengths were significantly different among these groups by one-way ANOVA, and the villi in the $10 \mathrm{mg}$ of SCBLC casein/ $\mathrm{mL}$ group was significantly longer than those in any of the other groups by the post hoc Fisher PLSD test (test 4 in Table 1). The differences in percentages of PCNApositive cells among these groups were similar to those in the intestinal villus length. The PCNA-positive cells were distributed exclusively in the intestinal crypts in each group (Figure 5B). The percentages of PCNApositive cells were significantly different among these groups by one-way ANOVA, and the percentage in the $10 \mathrm{mg}$ of SCBLC casein/mL group was significantly greater than those in any of the other groups by the post hoc Fisher PLSD test (test 4 in Table 1). These results indicate that the active ingredient of SCBLC, which can facilitate the growth of intestinal villi and may protect the villi from IND-induced enteropathy, was present in the casein fraction.

\section{DISCUSSION}

The present study was performed to investigate the potential antiinflammatory and recovery effects of bovine late colostrum in an NSAID-induced intestinal
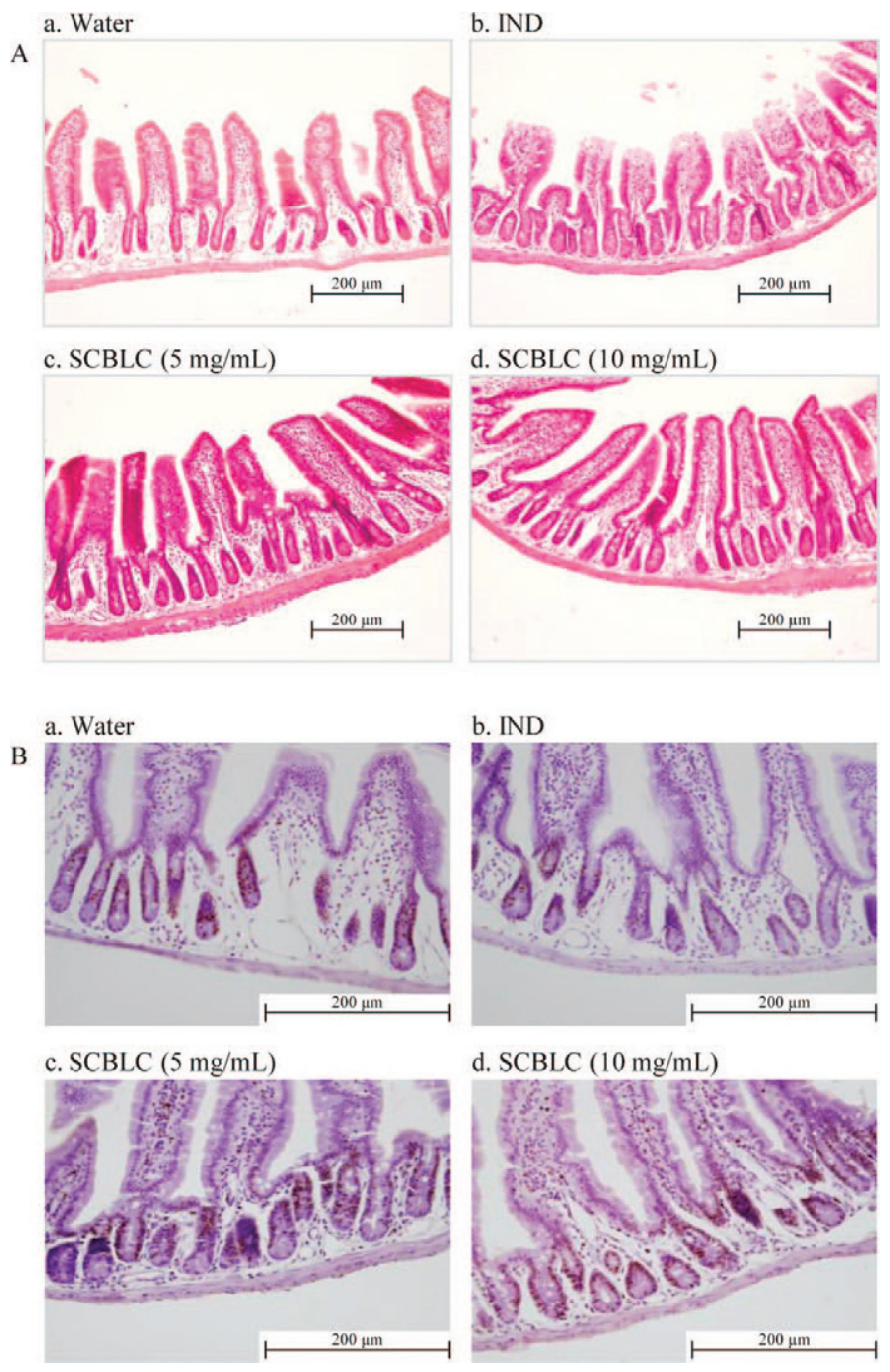

Figure 3. Preventive effects of skimmed and concentrated bovine late colostrum (SCBLC) on indomethacin (IND)-induced enteropathy. Figure 3A shows hematoxylin and eosin staining of the jejunum of mice. Figure 3B shows immunostaining for proliferating cells in the jejunum of mice for nuclear antigen (proliferating cell nuclear antigen, PCNA). Brown cells are positive and blue cells are negative. Mice were fed $5 \mathrm{mg} / \mathrm{mL}$ (c) or $10 \mathrm{mg} / \mathrm{mL}$ (d) of SCBLC for $6 \mathrm{~d}$, and then $85 \mathrm{mg}$ of IND $/ \mathrm{kg}$ was administered subcutaneously (b, c, and d). As a control, a tissue section from an untreated (a) animal is shown. The bars indicate $200 \mu \mathrm{m}$.

injury mouse model. Colostrum feeding stimulated the proliferation of immature epithelial cells in the intestinal crypts, leading to the growth of intestinal villi in the normal adult mouse small intestine (Figure 2 and test 1 in Table 1 ). The lengths of each of 70 villi per mouse $(\mathrm{n}=3)$ were measured, showing that SCBLC is effective in intestinal mucosa cell proliferation. These results correspond to previous reports that colostrum is rich in growth factors that have growth effects on rat intestinal cells (Playford et al., 1999; An et al., 2009). Skimmed and concentrated bovine late colostrum is 


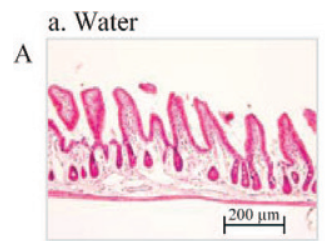

b. IND

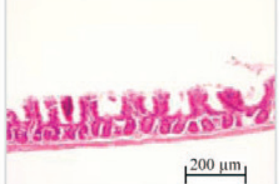

c. $\operatorname{SCBLC}(10 \mathrm{mg} / \mathrm{mL})$
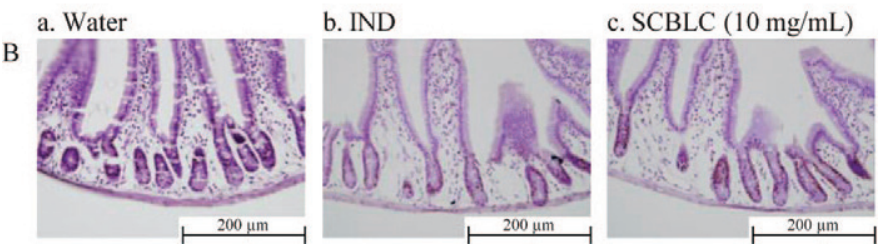

Figure 4. Healing effects of skimmed and concentrated bovine late colostrum (SCBLC) on indomethacin (IND)-induced enteropathy. Figure $4 \mathrm{~A}$ shows hematoxylin and eosin staining of the jejunum of mice. Figure $4 \mathrm{~B}$ shows immunostaining for proliferating cells in the jejunum of mice for nuclear antigen (proliferating cell nuclear antigen, PCNA). Brown cells are positive and blue cells are negative. Mice were injected with $20 \mathrm{mg}$ of IND/ $\mathrm{kg}$ for $2 \mathrm{~d}$ (b and c) and then fed 10 $\mathrm{mg}$ of SCBLC $/ \mathrm{mL}$ (c) for $1 \mathrm{wk}$. As a control, a tissue section from an untreated (a) animal is shown. The bars indicate $200 \mu \mathrm{m}$.

thought to contain higher levels of insulin-like growth factors and transforming growth factor- $\beta$ than normal milk.

Nonsteroidal antiinflammatory drugs inhibit the prostaglandin-producing enzyme cyclooxygenases (COX) and long-term treatment can induce serious complications, such as gastrointestinal damage (Miura et al., 2007). Moreover, colostrum exerted an inhibitory effect on IL-1 $\beta$-induced COX-2 expression in a timeand dose-dependent manner in HT-29 cells (An et al., 2009). Our results suggested that prefeeding with both concentrations of colostrum stimulated the proliferation of immature epithelial cells of the intestinal villi, avoiding the reduction of intestinal cell proliferation by IND, and prefeeding with $10 \mathrm{mg} / \mathrm{mL}$ of colostrum can facilitate the growth of intestinal villi even in the case of IND-induced enteropathy (Figure 3 and test 2 in Table 1). However, little in vivo research has been done exploring the protective and recovery effects of SCBLC against intestinal inflammation. We hypothesized that bovine late colostrum may also modulate intestinal inflammation in mice. To examine this hypothesis, we investigated the effect of bovine late colostrum on a mouse model of NSAID-induced intestinal injury. Colostrum inhibits small intestinal injury in rats induced by IND (Playford et al., 1999; An et al., 2009). Colostrum blocks IL-1 $\beta$-induced proinflammatory gene expression and COX-2 protein expression in human colon

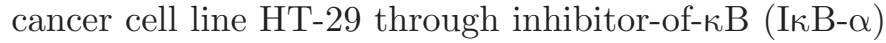
degradation and inhibition of nuclear factor $\kappa \mathrm{B}$ (NF$\kappa B$ ) signaling (An et al., 2009). Inhibition of NF- $\mathrm{BB}$
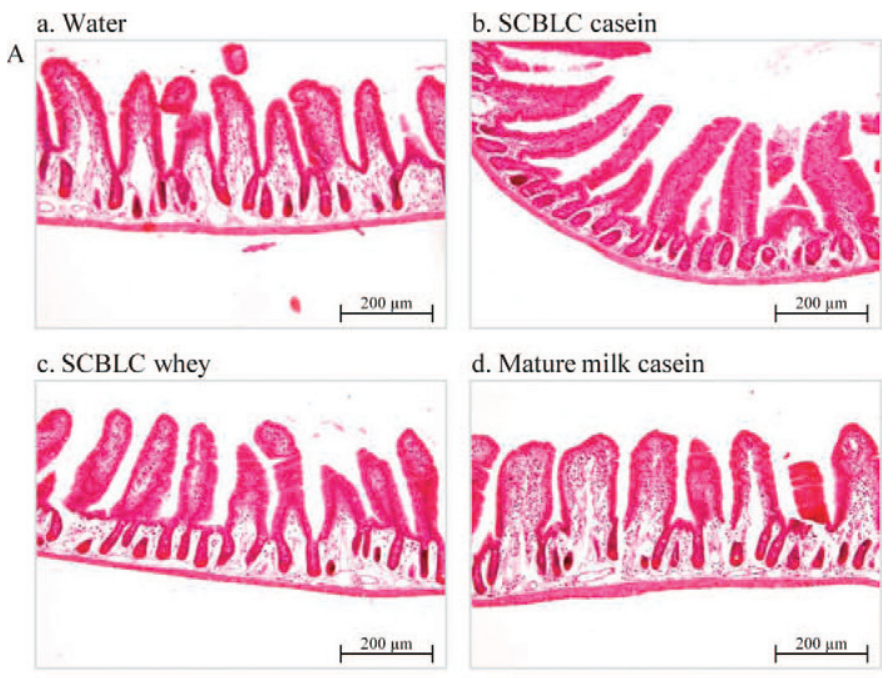

d. Mature milk casein
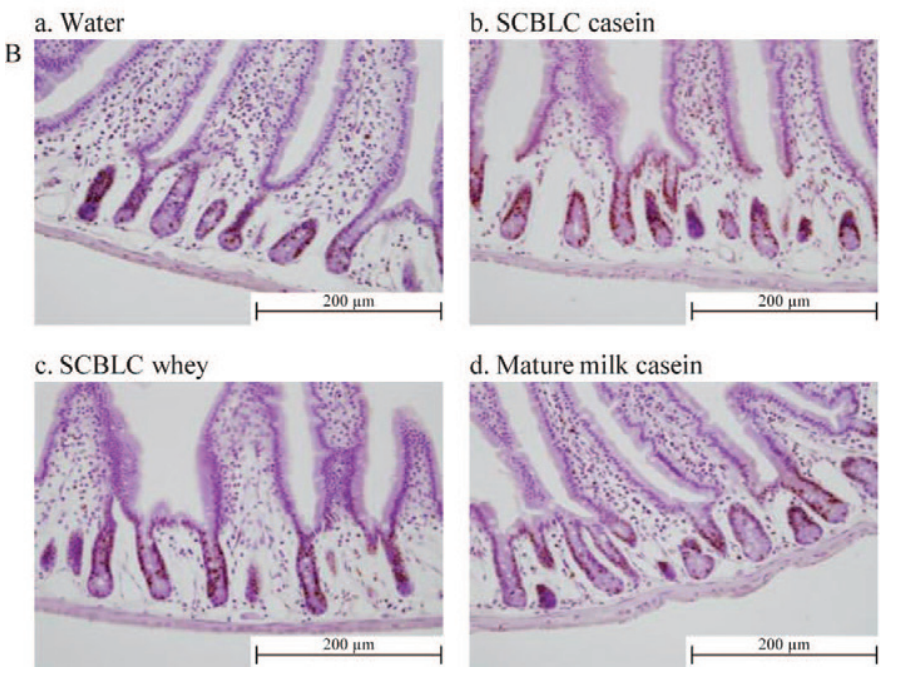

Figure 5. Effects of skimmed and concentrated bovine late colostrum (SCBLC) casein and whey on the normal small intestine. Figure $5 \mathrm{~A}$ shows hematoxylin and eosin staining of the jejunum of mice. Figure 5B shows immunostaining for proliferating cells in the jejunum of mice for nuclear antigen (proliferating cell nuclear antigen, PCNA). Brown cells are positive and blue cells are negative. Mice were fed 10 $\mathrm{mg} / \mathrm{mL}$ of colostrum casein (b), whey (c), or milk casein (d). As a control, a tissue section from an untreated (a) animal is shown. The bars indicate $200 \mu \mathrm{m}$.

activation is an attractive therapeutic strategy for a wide range of human diseases, including inflammatory bowel disease (Brooks et al., 2006; An et al., 2009). Our results were consistent with their studies.

In the present study, bovine late colostrum might inhibit intestinal inflammation by inhibiting decreases in number of COX-2-positive cells among the intestinal mucosal cells by IND. This effect was suggested to be related to the growth and tissue repair factors contained in colostrum (Playford et al., 1999). Those authors suggested that bovine late colostrum may inhibit the 
decline in COX-2 level in the lamina propria mucosa of the small intestine and the decline in prostaglandin E2 (PGE2) level in the small intestinal mucosa by IND. Current therapeutic options include coadministration of damage-limiting drugs, particularly acid suppressants and prostaglandin analogs, or using relatively selective COX-II inhibitors.

Next, we examined the healing effect of colostrum on IND-induced enteropathy. The results suggest that immediate and continuous treatment of IND-induced enteropathy by colostrum feeding can stimulate recovery of the intestinal villi to the normal level in the mouse small intestine (Figure 4 and test 3 in Table 1). Colostrum has been reported to play a role in IGF-I (Mero et al., 1997), recovery of loose bowels caused by virus infection (Rump et al., 1992), and early recovery of enteritis symptoms (Bjarnason et al., 1986; Playford et al., 2001). Colostrum may be beneficial in neonatal intestinal development and tissue repair after intestinal injury (Goldman, 2000; Buccigrossi et al., 2007). In addition, bovine late colostrum ameliorated diarrhea symptoms caused by human rotavirus infection in mice (Inagaki et al., 2010). Our results showed that bovine late colostrum ameliorated small intestinal villus damage and the decline in PCNA-positive cell level caused by IND. These data were consistent with those of the aforementioned studies. Therefore, the findings reported here demonstrated that SCBLC ameliorated intestinal inflammation caused by IND, thought to be due to the presence of many growth factors and immune factor in colostrum.

In addition, the active ingredients in SCBLC proteins, exerted into cells on the normal small intestinal mucosa, were identified. The casein fraction from SCBLC was shown to increase both villus length and PCNA-positive cell number in the small intestine of normal mice (Figure 5 and test 4 in Table 1). Casein, making up $80 \%$ of the proteins in bovine milk, mainly consists of 4 casein phosphoproteins; $\alpha \mathrm{S}_{1^{-}}, \alpha \mathrm{S}_{2^{-}}, \beta-$, and $\kappa$-CN (Eigel et al., 1984). All 4 caseins are amphiphilic and have ambiguous structures (Fox, 2003; Thompson et al., 2009) and have distinct hydrophobic and hydrophilic domains (Dalgleish, 1998; Anal et al., 2008). Furthermore, the sialylated glycoprotein $\kappa-\mathrm{CN}$ has only 1 phosphate and 14 carboxylic acid groups located in the hydrophilic C-terminal region called the glycomacropeptide (Dalgleish, 1998; Anal et al., 2008). Several reports showed that casein proteins are tract factors of regulators for the immune system, such that $\kappa$-caseinoglycopeptides with different carbohydrate chains inhibit mitogen-induced proliferative responses of $\mathrm{B}$ and $\mathrm{T}$ lymphocytes, when weak in pepsin activity (Otani et al., 1995). However, no reports exist that casein proteins effect proliferation of intestinal cells, although lactoferrin, a minor protein of the whey fraction, has been identified as a factor in human colostrum that accounts for increased incorporation of thymidine into the DNA in an in vitro rat crypt enterocyte bioassay (Nichols et al., 1989, 1990). The present study is the first report demonstrating that the casein fraction effected the proliferation of small intestinal cells. Interestingly, the casein fraction separated from mature milk did not show the effects and only the SCBLC casein had such effects. The difference between caseins from mature milk and SCBLC are unclear. We will characterize the SCBLC casein in further studies.

\section{CONCLUSIONS}

This study demonstrated that the casein fraction is the active ingredient in bovine late colostrum involved in the recovery and inhibition of NSAID-induced small intestinal injury in a mouse model of intestinal tissue cells. Inhibition and recovery of small intestinal injury is an attractive therapeutic strategy for a wide range of human diseases, including inflammatory bowel disease. Demonstrating its potential healing and prophylactic role against necrotizing enterocolitis, bovine late colostrum may be representative of a new class of antiinflammatory agents that could be used to treat inflammatory intestinal disorders.

\section{REFERENCES}

An, M. J., J. H. Cheon, S. W. Kim, J. J. Park, C. M. Moon, S. Y. Han, E. S. Kim, T. I. Kim, and W. H. Kim. 2009. Bovine colostrum inhibits nuclear factor $\kappa$ B-mediated proinflammatory cytokine expression in intestinal epithelial cells. Nutr. Res. 29:275-280.

Anal, A. K., A. Tobiassen, J. Flanagan, and H. Singh. 2008. Preparation and characterization of nanoparticles formed by chitosancaseinate interactions. Colloids Surf. B Biointerfaces 64:104-110.

Bjarnason, I., P. Williams, P. Smethurst, T. J. Peters, and A. J. Levi. 1986. Effect of non-steroidal anti-inflammatory drugs and prostaglandins on the permeability of the human small intestine. Gut 27:1292-1297.

Bjarnason, I., G. Zanelli, T. Smith, P. Smethurst, A. B. Price, M. J. Gumpel, and A. J. Levi. 1987. The pathogenesis and consequence of non steroidal anti-inflammatory drug induced small intestinal inflammation in man. Scand. J. Rheumatol. Suppl. 64:55-62.

Brooks, H. J., M. A. McConnell, J. Corbett, G. S. Buchan, C. E. Fitzpatrick, and R. S. Broadbent. 2006. Potential prophylactic value of bovine colostrum in necrotizing enterocolitis in neonates: An in vitro study on bacterial attachment, antibody levels and cytokine production. FEMS Immunol. Med. Microbiol. 48:347-354.

Buccigrossi, V., G. de Marco, E. Bruzzese, L. Ombrato, I. Bracale, G. Polito, and A. Guarino. 2007. Lactoferrin induces concentrationdependent functional modulation of intestinal proliferation and differentiation. Pediatr. Res. 61:410-414.

Dalgleish, D. G. 1998. Casein micelles as colloids: Surface structures and stabilities. J. Dairy Sci. 81:3013-3018.

Eigel, W. N., J. E. Butler, C. A. Ernstrom, H. M. Farrell Jr., V. R. Harwalkar, R. Jenness, and R. M. Whitney. 1984. Nomenclature of proteins of cow's milk: Fifth revision. J. Dairy Sci. 67:1599-1631.

Fang, W. F., A. Broughton, and M. D. Jacobson. 1977. Indomethacininduced intestinal inflammation. Am. J. Dig. Dis. 22:749-760. 
Fox, P. F. 2003. Milk proteins: General and historical aspects. Pages 1-48 in Advanced Dairy Chemistry, Vol. 1: Proteins. Part A. P. F. Fox and P. L. H. McSweeney, ed. Kluwer Academic/Plenum Publishers, New York, NY.

Fukumoto, K., Y. Naito, T. Takagi, S. Yamada, R. Horie, K. Inoue, A. Harusato, I. Hirata, T. Omatsu, K. Mizushima, Y. Hirai, N. Yoshida, K. Uchiyama, T. Ishikawa, O. Handa, H. Konishi, N. Wakabayashi, N. Yagi, S. Kokura, H. Ichikawa, M. Kita, and T. Yoshikawa. 2011. Role of tumor necrosis factor- $\alpha$ in the pathogenesis of indomethacin-induced small intestinal injury in mice. Int. J. Mol. Med. 27:353-359.

Goldman, A. S. 2000. Modulation of the gastrointestinal tract of infants by human milk. Interfaces and interactions. An evolutionary perspective. J. Nutr. 130:426S-431S.

Howarth, G. S., G. L. Francis, J. C. Cool, X. Xu, R. W. Byard, and L. C. Read. 1996. Milk growth factors enriched from cheese whey ameliorate intestinal damage by methotrexate when administered orally to rats. J. Nutr. 126:2519-2530.

Huppertz, H.-I., S. Rutkowski, D. H. Busch, R. Eisebit, R. Lissner, and H. Karch. 1999. Bovine colostrum ameliorates diarrhea in infection with diarrheagenic Escherichia coli, Shiga toxin-producing E. coli, and E. coli expressing intimin and hemolysin. J. Pediatr. Gastroenterol. Nutr. 29:452-456.

Inagaki, M., M. Yamamoto, Xijier, Cairangzhuoma, K. Uchida, H. Yamaguchi, M. Kawasaki, K. Yamashita, T. Yabe, and Y. Kanamaru. 2010. In vitro and in vivo evaluation of the efficacy of bovine colostrum against human rotavirus infection. Biosci. Biotechnol. Biochem. 74:680-682.

Kelly, G. S. 2003. Bovine colostrums: A review of clinical uses. Altern. Med. Rev. 8:378-394.

Khan, Z., C. Macdonald, A. C. Wicks, M. P. Holt, D. Floyd, S. Ghosh, N. A. Wright, and R. J. Playford. 2002. Use of the 'nutriceutical', bovine colostrum, for the treatment of distal colitis: Results from an initial study. Aliment. Pharmacol. Ther. 16:1917-1922.

Lee, J., S.-H. Kwon, H.-M. Kim, S. N. Fahey, D. R. Knighton, and A. Sansom. 2008. Effect of a growth protein-colostrum fraction on bone development in juvenile rats. Biosci. Biotechnol. Biochem. $72: 1-6$.

Mero, A., H. Miikkulainen, J. Riski, R. Pakkanen, J. Aalto, and T. Takala. 1997. Effects of bovine colostrum supplementation on serum IGF-I, IgG, hormone, and saliva IgA during training. J. Appl. Physiol. 83:1144-1151.

Miura, N., M. Fukutake, M. Yamamoto, N. Ohtake, S. Iizuka, S. Imamura, N. Tsuchiya, M. Ishimatsu, Y. Nakamura, A. Ishige, K. Watanabe, Y. Kase, and S. Takeda. 2007. An herbal medicine orengedokuto prevents indomethacin-induced enteropathy. Biol. Pharm. Bull. 30:495-501.

Murakami, K., S. Suzuki, N. Aoki, T. Okajima, D. Nadano, K. Uchida, K. Yamashita, T. Oka, K. Katayama, N. Takeda, and T. Matsuda. 2010. Binding of norovirus virus-like particles (VLPs) to human intestinal Caco-2 cells and the suppressive effect of pasteurized bovine colostrum on this VLP binding. Biosci. Biotechnol. Biochem. 74:541-547.

Nichols, B. L., K. S. McKee, J. F. Henry, and V. N. Nichols. 1989. Human lactoferrin supplementation of infant formulas increases thymidine incorporation into the DNA of rat crypt cells. J. Pediatr. Gastroenterol. Nutr. 8:102-109

Nichols, B. L., K. S. McKee, and H. A. Huebers. 1990. Iron is not required in the lactoferrin stimulation of thymidine incorporation into the DNA of rat crypt enterocytes. Pediatr. Res. 27:525-528.

Otani, H., M. Monnai, Y. Kawasaki, H. Kawakami, and M. Tanimoto. 1995. Inhibition of mitogen-induced proliferative responses of lymphocytes by bovine $\kappa$-caseinoglycopeptides having different carbohydrate chains. J. Dairy Res. 62:349-357.

Playford, R. J., D. N. Floyd, C. E. Macdonald, D. P. Calnan, R. O. Adenekan, W. Johnson, R. A. Goodlad, and T. Marchbank. 1999. Bovine colostrum is a health food supplement which prevents NSAID induced gut damage. Gut 44:653-658.

Playford, R. J., C. E. MacDonald, D. P. Calnan, D. N. Floyd, T. Podas, W. Johnson, A. C. Wicks, O. Bashir, and T. Marchbank. 2001. Coadministration of the health food supplement, bovine colostrum reduces the acute non-steroidal anti-inflammatory drug-induced increase in intestinal permeability. Clin. Sci. 100:627-633.

Robert, A., and T. Asano. 1977. Resistance of germfree rats to indomethacin induced intestinal lesions. Prostaglandins 14:333-341.

Rump, J. A., R. Arndt, A. Arnold, C. Bendick, H. Dichtelmüller, M. Franke, E. B. Helm, H. Jäger, B. Kampmann, P. Kolb, W. Kreuz, R. Lissner, W. Meigel, P. Ostendorf, H. H. Peter, A. Plettenberg, I. Schedel, H. W. Stellbrink, and W. Stephan. 1992. Treatment of diarrhoea in human immunodeficiency virus-infected patients with immunoglobulins from bovine colostrum. Clin. Invest. 70:588594

Sarker, S. A., T. H. Casswall, D. Mahalanabis, N. H. Alam, M. J. Albert, H. Brüssow, G. J. Fuchs, and L. Hammerström. 1998. Successful treatment of rotavirus diarrhea in children with immunoglobulin from immunized bovine colostrum. Pediatr. Infect. Dis. J. 17:1149-1154.

Thompson, A., M. J. Boland, and H. Singh. 2009. Milk Proteins: From Expression to Food. 1st ed. S. L. Taylor, series ed. Elsevier, Academic Press, Amsterdam, the Netherlands. 